\title{
PEMELIHARAAN LARVA IKAN KAKAP PUTIH (Lates calcarifer) DENGAN PADAT PENEBARAN YANG BERBEDA
}

\author{
Yunus*
}

\begin{abstract}
ABSTRAK
Dalam usaha pembenihan ikan kakap putih, informasi tentang padat penebaran yang optimal merupakan hal yang sangat penting dalam upaya mendapatkan produksi benih yang optimal. Dua percobaan dilakukan untuk mengetahui padat penebaran yang optimal dalam pemeliharaan larva ikan kakap putih di laboratorium. Pada percobaan pertama larva dipelihara dari saat menetas sampai dengan larva berumur 12 hari. Larva yang baru menetas ditebar dalam 12 buah bak serat gelas berbentuk silinder, masing-masing diisi $500 \mathrm{~L}$ air laut bersih dan diaerasi. Perlakuan percobaan adalah padat penebaran yang berbeda, yaitu 10, 30, 50, dan 70 ind./L dengan tiga ulangan pada setiap perlakuan. Larva diberi pakan berupa rotifer dan Nannochloropsis sp. Pergantian air dilakukan setiap hari sebanyak $25 \%$ dari volume total. Pada percobaan ke dua larva dipelihara dari umur 13 hari sampai dengan umur 30 hari. Pemeliharaan larva menggunakan 12 buah bak polikarbonat yang diisi $30 \mathrm{~L}$ air laut bersih dan diaerasi. Sebagai perlakuan adalah padat penebaran yang berbeda, yaitu 10, 20, 30, dan 40 ind./L. Pakan yang diberikan pada larva adalah rotifer, Nannochloropsis sp. dan nauplii artemia. Pergantian air dilakukan setiap hari sebanyak $50 \%$ dari volume total. Hasil analisis ragam menunjukkan bahwa pada percobaan pertama dan ke dua, perlakuan padat penebaran berpengaruh nyata $(P<0,05)$ terhadap panjang total dan sintasan larva ikan kakap putih. Padat penebaran optimal untuk pemeliharaan larva ikan kakap putih dari saat menetas sampai dengan umur 12 hari adalah antara 10-50 ind./L, sedangkan untuk pemeliharaan larva ikan kakap putih dari umur 13 hari sampai dengan umur 30 hari, padat penebaran yang optimal adalah antara 10-20 ind./L
\end{abstract}

\begin{abstract}
Larval rearing of seabass (Lates calcarifer) at different stocking densities. By: Yunus.

Concerning the larval rearing of seabass, information of optimal stocking density is prime importance to support the effort on achieving the optimal seed production. Two experiments were conducted to estimate the optimal stocking density of seabass larvae reared at the laboratory. In the first experiment seabass larvae were reared from hatching until 12 day-old larvae. The newly hatched larvae were stocked in 12 round fiberglass tanks, each filled with 500 liters of filtered seawater and provided with aeration. Four stocking densities as treatments were tested i.e. 10, 30, 50 and $70 \mathrm{ind} . / \mathrm{L}$. Each treatment three replicates. Live food for the larval rearing consisted of rotifer and the microalga Nannochloropsis sp. Culture water was changed daily at a rate of $25 \%$ of the volume. In the second experiment seabass larvae were reared from 13 day-old until 30 dayold larvae. The larval rearing was carried out in 12 polycarbonate tanks filled with 30 liters of filtered and aerated seawater. The treatments applied were four stocking densities, i.e., 10, 20, 30 and 40 ind./L. Three replicates were used for each treatment. Larvae were fed with rotifer, Nannochloropsis sp. and artemia nauplii. Daily water renewal rate in all the tanks was maintained at $50 \%$ of the water volume. Results showed that in both experiment 1 and 2, stocking density significantly $(P<0.05)$ affected the total length and survival of seabass larvae. The optimal stocking density for rearing seabass larvae from hatching until 12 day-old larvae was between 10 and 50 ind./L, whereas for rearing seabass larvae from 13 day-old until 30 day-old larvae, the optimal stocking density was between 10 and 20 ind./L.
\end{abstract}

KEYWORDS: larval rearing, stocking density, seabass

\section{PENDAHULUAN}

Ikan kakap putih (Lates calcarifer) termasuk jenis ikan yang mempunyai toleransi yang tinggi terhadap perubahan salinitas (Grey, 1986) dan karena itu jenis ikan ini dapat hidup di perairan sungai, danau, estuari, dan teluk (Garcia et al., 1988). Dengan adanya sifat hidup yang dimiliki itu pula maka ikan kakap putih dapat dibudidayakan baik di kolam air tawar maupun tambak air payau dan juga dapat dibudidayakan di karamba jaring apung di laut (Castanos, 1997; Aldon, 1997).

Ikan kakap putih merupakan salah satu jenis ikan budi daya yang mempunyai nilai ekonomi penting di Asia Tenggara dan Australia (Garcia et al., 1988; Kohno et al., 1996). Di Indonesia budi daya ikan kakap putih termasuk salah satu kegiatan usaha budi daya

\footnotetext{
Peneliti pada Loka Penelitian Perikanan Pantai
} 
laut yang telah berkembang dan sudah dikuasai teknologinya oleh masyarakat atau pengusaha (Ramelan, 1999; Akiyama et al., 1998). Harga ikan laut hidup untuk jenis kakap putih hasil budi daya di Kepulauan Riau berkisar antara US\$9-US\$11 per kg (Sugama, 1999).

Faktor utama yang dibutuhkan untuk mendukung keberhasilan budi daya ikan adalah tersedianya benih yang kontinyu baik dalam jenis, jumlah maupun mutunya (Ramelan. 1998). Sampai saat ini sebagian besar pasok benih ikan yang sedang dibudidayakan masih berasal dari hasil tangkapan di alam (Sugama, 1999). Oleh karena itu untuk mengurangi ketergantungan benih dari alam, perlu adanya penguasaan teknologi pembenihan untuk ikan yang dibudidayakan sehingga dengan demikian dapat diproduksi benihnya secara massal untuk mendukung kelancaran usaha budi daya ikan itu sendiri. Penelitian pembenihan ikan kakap putih sudah banyak dilakukan, di antaranya adalah pemijahan induk ikan kakap putih dengan perangsangan hormonal, seperti pemakaian hormon HCG dan Puberogen (Santosa \& Notowinarto, 1991), perangsangan pemijahan induk dengan manipulasi lingkungan seperti salinitas, suhu, dan kedalaman air (Notowinarto \& Santosa, 1991; Yasa et al., 1999) serta penelitian-penelitian yang menyangkut aspek pemeliharaan larva ikan kakap putih (Purba \& Mayunar, 1990; Supriatna et al., 1990; Slamet et al., 1991; Redjeki et al., 1993). Namun demikian produksi benih ikan kakap putih yang dihasilkan umumnya masih dalam skala penelitian dan masih perlu dikembangkan lebih lanjut. Sugama (1999) melaporkan bahwa benih ikan kakap putih hasil pembenihan hatcheri sampai saat ini masih berasal dari impor.

Dalam usaha pembenihan ikan kakap putih, informasi tentang padat penebaran optimal merupakan hal yang sangat penting untuk mendukung upaya menghasilkan produksi benih yang optimal. Penelitian ini berkaitan dengan pemeliharaan larva ikan kakap putih dengan padat penebaran yang berbeda dari saat larva baru menetas sampai dengan larva berumur 12 hari dan selanjutnya dari larva berumur 13 hari sampai dengan larva berumur 30 hari. Menurut Comdej (1986) dalam Mayunar et al. (1990), larva ikan kakap putih pada umur 12-15 hari sudah memperlihatkan sifat kanibalisme. Ramelan (1999) mengemukakan bahwa benih ikan kakap putih siap dipanen pada umur 30 hari (D-30). Tujuan penelitian ini adalah untuk mengetahui padat penebaran yang optimal dalam pemeliharaan larva ikan kakap putih.

\section{BAHAN DAN METODE}

Percobaan dilakukan di Laboratorium Loka Penelitian Perikanan Pantai Gondol, Bali. Percobaan terdiri atas dua tahap, yaitu percobaan I adalah pemeliharaan larva dari saat menetas sampai dengan larva berumur 12 hari dan percobaan II adalah pemeliharaan larva dari umur 13 hari sampai dengan umur 30 hari. Selanjutnya setiap tahapan percobaan dapat dikemukakan sebagai berikut.

Pada percobaan pertama larva ikan kakap putih yang digunakan berasal dari telur yang memijah secara alami dari induk ikan kakap putih yang dipelihara secara terkontrol dalam bak beton volume $50 \mathrm{~m}^{3}$ dengan sistem air mengalir yang dilengkapi aerasi. Larva yang baru menetas ditebar dalam 12 buah bak serat gelas berbentuk silinder yang ditempatkan dalam ruangan dengan atap terbuat dari serat gelas. Setiap bak pemeliharaan larva diisi air laut yang telah disaring dengan kantong filter dalam volume sebanyak $500 \mathrm{~L}$ dan dilengkapi aerasi. Larva diberi pakan setiap hari berupa rotifer dengan kepadatan 5-15 ind./mL yang dimulai dari hari ke-2. Selain pakan tersebut setiap hari ke dalam media pemeliharaan juga ditambahkan Nannochloropsis sp. dengan kepadatan antara $3 \times 10^{5}-5 \times 10^{5} \mathrm{sel} / \mathrm{mL}$ yang dimulai dari hari ke-1. Penambahan fitoplankton tersebut selain untuk menstabilkan kondisi media pemeliharaan larva (Sumiarsa et al., 1994; Yunus et al., 1998) juga sebagai pakan rotifer yang berada dalam bak pemeliharaan larva.

Rancangan percobaan yang digunakan adalah rancangan acak lengkap dengan empat perlakuan dan tiga ulangan. Perlakuan percobaan adalah padat penebaran larva yang berbeda, yaitu 10,30, 50 dan 70 ind./L. Pergantian air dilakukan setiap hari sebanyak $25 \%$ dari volume total. Percobaan berakhir pada hari ke-12 atau pada saat larva berumur 12 hari.

Pada percobaan kedua digunakan larva ikan kakap putih berumur 13 hari yang berasal dari hasil percobaan pertama. Wadah yang digunakan untuk pemeliharaan larva berupa bak polikarbonat berjumlan 12 buah. Setiap bak diisi air laut yang telah disaring dengan kantong filter masing-masing sebanyak $30 \mathrm{~L}$ dan dilengkapi dengan aerasi. Pakan larva yang diberikan adalah rotifer dengan kepadatan 20-30 ind./ $\mathrm{mL}$ dan Nannochloropsis sp. dengan kepadatan $3 \times$ $10^{5}-5 \times 10^{5} \mathrm{sel} / \mathrm{mL}$ yang dimulai pada hari ke-13 (saat penebaran) sampai dengan hari ke 23 (Sunyoto et al., 1990). Nauplii artemia diberikan dengan kepadatan 1-2 ind./mL mulai hari ke-19 (Sunyoto \& Basyari, 1990) sampai dengan akhir percobaan.

Rancangan percobaan yang digunakan adalah rancangan acak lengkap dengan empat perlakuan dan tiga ulangan. Sebagai perlakuan adalah padat penebaran larva yang berbeda, yaitu 10, 20,30, dan 40 ind./L. Pergantian air dilakukan setiap hari sebanyak $50 \%$ dari volume total. Percobaan berakhir pada hari ke-30. 
Tabel 1. Panjang total dan sintasan larva ikan kakap putih (Lates calcarifer) dengan padat penebaran berbeda pada harike-12

Table 1. Total length and survival of seabass (Lates calcarifer) larvae at different stocking densities on day 12

Padat penebaran/Stocking density Panjang total/Total length Sintasan/Survival rate (ind./L) $(\mathrm{mm})$

$(\%)$

\begin{tabular}{lll}
\hline 10 & $5.65 \pm 0.27^{\mathrm{a}}$ & $76.67 \pm 5.77^{\mathrm{a}}$ \\
30 & $5.22 \pm 0.21^{\mathrm{a}}$ & $64.45 \pm 10.72^{\mathrm{a}}$ \\
50 & $5.04 \pm 0.33^{\mathrm{ab}}$ & $62.67 \pm 11.72^{\mathrm{a}}$ \\
70 & $4.54 \pm 0.45^{\mathrm{a}}$ & $44.76 \pm 8.61^{\mathrm{b}}$ \\
\hline
\end{tabular}

Angka dalam kolom diikuti huruf yang sama tidak berbeda nyata (Values in column followed by the same letter are not significantly different) ( $P>0.05$ )

Parameter yang diamati pada percobaan tahap pertama dan ke dua adalah ukuran (panjang total) dan sintasan larva serta kualitas air. Pengukuran panjang total larva dilakukan dengan menggunakan mikroskop yang dilengkapi dengan mikrometer

\section{HASIL. DAN BAHASAN}

Pada percobaan pertama larva ikan kakap putih yang baru menetas mempunyai panjang total $1,65 \pm 0,07 \mathrm{~mm}$ dengan kuning telur berukuran panjang $973 \pm 47 \mathrm{~mm}$, lebar $580 \pm 24 \mathrm{~mm}$ dan butir minyak dengan diameter $307 \pm 12 \mathrm{~mm}$. Selanjutnya setelah masa pemeliharaan sampai dengan umur 12 hari (Tabel 1) panjang total larva untuk perlakuan padat penebaran 10,30, 50 dan 70 ind./L masing-masing mencapai $5,65 \pm 0,27 \mathrm{~mm} ; 5,22 \pm 0,21 \mathrm{~mm} ; 5,04 \pm 0,33$

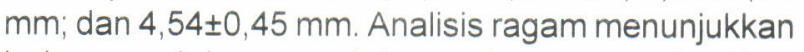
bahwa perlakuan padat penebaran memberikan pengaruh yang nyata $(P<0,05)$ terhadap panjang total larva. Antara perlakuan padat penebaran 10,30 dan 50 ind. $/ L$ tidak berbeda nyata, tetapi perlakuan padat penebaran 10 dan 30 ind. $/ L$ berbeda nyata dengan perlakuan padat penebaran 70 ind./L, sedangkan antara perlakuan padat penebaran 50 dan 70 ind./L tidak berbeda nyata.
Dari data sintasan larva pada umur 12 hari (Tabel 1) menunjukkan bahwa perlakuan padat penebaran $10,30,50$, dan 70 ind./L. masing-masing menghasilkan sintasan larva sebesar $76,67 \pm 5,77 \% ; 64,45 \pm 10,72 \%$; $62,67 \pm 11,72 \%$ dan $44,76 \pm 8,61 \%$. Berdasarkan analisis ragam ternyata terdapat pengaruh yang nyata $(P<0,05)$ dari perlakuan terhadap sintasan larva. Perlakuan padat penebaran 10,30 , dan 50 ind./L masing-masing tidak berbeda satu sama lainnya, tetapi masing-masing berbeda dengan perlakuan padat penebaran 70 ind./L.

Pada percobaan ke dua, panjang total larva umur 30 hari tertinggi dicapai pada perlakuan padat penebaran 10 ind $/ / \mathrm{L}(12,66 \pm 0,39 \mathrm{~mm})$, kemudian diikuti perlakuan padat penebaran 20,30 , dan 40 ind. L masing-masing mencapai panjang total $11,72 \pm 0,90$ $\mathrm{mm}, 10,87 \pm 0,21 \mathrm{~mm}$ dan 9,66 $\pm 0,49 \mathrm{~mm}$ (Tabel 2). Berdasarkan analisis statistik ternyata panjang total menunjukkan perbedaan yang nyata antar perlakuan $(\mathrm{P}<0,05)$. Perlakuan padat penebaran 10 ind. $/ \mathrm{L}$ tidak berbeda nyata dengan perlakuan padat penebaran 20 ind./L, tetapi berbeda nyata dengan perlakuan padat penebaran 30 dan 40 ind./L. Perlakuan padat penebaran 20 ind./L tidak berbeda nyata dengan perlakuan padat penebaran 30 ind./L tetapi kedua

Tabel 2. Panjang total dan sintasan larva ikan kakap putih (Lates calcarifer) dengan padat penebaran berbeda pada hari ke-30

Table 2. Total length and survival rate of seabass (Lates calcarifer) larvae at different stocking densities on day 30

\begin{tabular}{ccc}
$\begin{array}{c}\text { Padat penebaran/Stocking density } \\
\text { (ind./L) }\end{array}$ & $\begin{array}{c}\text { Panjang total/Total length } \\
(\mathbf{m m})\end{array}$ & $\begin{array}{c}\text { Sintasan/Survival rate } \\
(\%)\end{array}$ \\
\hline 10 & $12.66 \pm 0.39^{\mathrm{a}}$ & $93.67 \pm 2.84^{\mathrm{a}}$ \\
20 & $11.72 \pm 0.90^{\mathrm{ab}}$ & $93.05 \pm 2.21^{\mathrm{a}}$ \\
30 & $10.87 \pm 0.21^{\mathrm{b}}$ & $86.78 \pm 0.33^{\mathrm{b}}$ \\
40 & $9.66 \pm 0.49^{\mathrm{c}}$ & $86.08 \pm 1.53^{\mathrm{b}}$
\end{tabular}

Angka dalam kolom dilkuti huruf y ang sama tidak berbeda nyata (Values in column followed by the same letter are not significantly different) $(P>0.05)$ 
perlakuan tersebut berbeda nyata dengan perlakuan padat penebaran 40 ind./L.

Selanjutnya dari Tabel 2 terlihat bahwa perlakuan padat penebaran 10 ind./L menghasilkan sintasan larva tertinggi pada hari ke-30 yaitu $93,67 \pm 2,84 \%$, kemudian disusul perlakuan padat penebaran 20,30, dan 40 ind./L masing-masing memberikan sintasan larva $93,05 \pm 2,21 \% ; 86,78 \pm 0,33 \%$; dan $86,08 \pm 1,53 \%$. Analisis ragam menunjukkan bahwa perlakuan padat penebaran memberikan pengaruh yang nyata $(P<0,05)$ terhadap sintasan larva. Perlakuan padat penebaran 10 dan 20 ind. IL tidak berbeda nyata satu sama lain, tetapi kedua perlakuan tersebut berbeda nyata dengan perlakuan padat penebaran 30 dan 40 ind. $/ L$. Sedangkan antara perlakuan padat penebaran 30 dan 40 ind $/ L$ tidak berbeda nyata.

Pada percobaan pertama dan ke dua ter lihat bahwa makin tinggi padat penebaran makin rendah panjang total dan sintasan yang dihasilkan. Pada percobaan pertama yaitu pemeliharaan larva dari saat menetas sampai dengan umur 12 hari dengan kepadatan 50 ind. $/ L$, diperoleh hasil panjang total dan sintasan larva masing-masing sebesar $5,04 \pm 0,33 \mathrm{~mm}$ dan $62,67 \pm 11,72 \%$. Sedangkan pada percobaan Supriatna et al. (1990) yang berkaitan dengan pemeliharaan larva ikan kakap putih dari saat menetas sampai dengan umur 15 hari dengan kepadatan sekitar 100 ind $/ \mathrm{L}$, didapatkan panjang total dan sintasan masing-masing sebesar $3,66 \pm 0,37 \mathrm{~mm}$ dan $29,4 \%$. $\mathrm{Hal}$ ini menunjukkan bahwa bila jumlah larva terlalu padat dalam bak pemeliharaan maka pertumbuhan larva akan terhambat dan sintasan larva akan rendah.

Dalam kaitannya dengan sintasan larva, terlihat bahwa hasil sintasan larva yang baik pada percobaan pertama adalah pada padat penebaran larva antara 10 dan 50 ind. $/ L$, sedangkan pada percobaan ke dua adalah pada padat penebaran larva antara 10 dan 20 ind. $/ \mathrm{L}$. Hal ini sesuai dengan pendapat Maneewong et al. (1986) dalam Supriatna et al. (1991) yang menyarankan untuk larva ikan kakap putih yang berumur $1-12$ hari kepadatan yang ideal ialah 50 ind./ L, sedangkan pada saat larva telah berumur 13-29 hari kepadatan larva disarankan 10-20 ind./L.

Selanjutnya dapat diketahui bahwa untuk mendapatkan sintasan larva yang baik maka kisaran padat penebaran larva pada percobaan ke dua adalah relatif lebih rendah dibanding dengan pada percobaan pertama. Hal ini disebabkan karena pada percobaan ke dua sudah mulai terjadi sifat kanibalisme pada larva. Mayunar \& Purba (1990) pada percobaannya tentang pemeliharaan benih ikan kakap putih di keramba jaring apung dengan padat penebaran yang berbeda mengemukakan bahwa sintasan ikan kakap putih tertinggi terjadi pada padat penebaran rendah.
Selanjutnya dinyatakan bahwa hal tersebut berhubungan dengan sifat kanibalisme dan terjadinya persaingan dalam mengambil pakan pada padat penebaran yang tinggi.

Hasil pengamatan kualitas air menunjukkan bahwa suhu air $27,0-32,0^{\circ} \mathrm{C}$; salinitas 34-35 ppt; pH 7,638,$21 ;$ nitrit $0,110-1,837 \mathrm{mg} / \mathrm{L}$; dan amonia $0,073-1,395$ $\mathrm{mg} / \mathrm{L}$. Umumnya ikan tropis mempunyai toleransi terhadap suhu air dalam kisaran $25-35^{\circ} \mathrm{C}$ (Parker \& Davis, 1981 dalam Kohno \& Slamet, 1990). Hasil pengamatan kualitas air yang dilakukan oleh Aslianti et al. (1998) dalam penelitiannya memelihara larva ikan kerapu bebek (Cromileptes altivelis) dari saat menetas sampai dengan umur 30 hari didapatkan kandungan nitrit dan amonia masing-masing dengan kisaran 0,06-1,95 mg/L dan 0,07-1,37 mg/L. Diduga kondisi kualitas air dalam penelitian ini masih dalam batas yang layak bagi kehidupan larva ikan kakap putih.

\section{KESIMPULAN}

Pada percobaan pertama dan ke dua, perlakuan padat penebaran memberikan pengaruh yang nyata $(P<0,05)$ terhadap panjang total dan sintasan larva ikan kakap putih. Padat penebaran optimal untuk pemeliharaan larva ikan kakap putih dari saat menetas sampai dengan umur 12 hari adalah antara 10 dan 50 ind./L, sedangkan untuk pemeliharaan larva ikan kakap putih dari umur 13 hari sampai dengan umur 30 hari, padat penebarannya yang optimal adalah antara 10 dan 20 ind./L.

\section{DAFTAR PUSTAKA}

Akiyama, D.M. A.M. Anggawati, H. Tedjokoesoemo, N.C Maharti and A. Santoso. 1998. Seabass (Lates calcarifer) production in earthen ponds with pelleted fish. Prosiding Seminar Teknologi Perikanan Pantai, Denpasar 6-7 Agustus 1998. p:52-54.

Aldon, E. 1997. The culture of seabass. SEAFDEC Asian Aquaculture 19(4):14-17.

Aslianti, T., Wardoyo, J.H. Hutapea, S. Ismi dan K.M. Setiawati. 1998. Pemeliharaan larva kerapu bebek Cromileptes altivelis dalam wadah berbeda warna. Jurnal Penelitian Perikanan Indonesia 4(3):25-31.

Castanos, M. 1997. Aquaculture Department's breedinghatchery techniques. SEAFDEC Asian Aquaculture 19(4):18-21.

Garcia, L.M.B., M.N. Duray and A.T. Trino. 1988. Promise in seabass culture. SEAFDEC Asian Aquaculture $10(3): 3$

Grey, D.L. 1986. An overview of Lates calcarifer in Australia and Asia. ACIAR Proceeding (20):15-21.

Kohno, H. and B. Slamet. 1990. Growth, survival and feeding habits of early larval seabass Lates calcarifer reared at different thermal conditions. J. Penelitian Budi Daya Pantai, Terbitan Khusus 1:37-44. 
Kohno, H., R. O. Aguilar, A. Ohno and Y. Taki. 1996. Osteological development of the feeding apparatus in early stage larvae of the seabass, Lates calcarifer. Ichthyological Research 43(1):1-9.

Mayunar dan R. Purba. 1990. Pengaruh padat penebaran terhadap pertumbuhan dan kelulushidupan kakap putih, Lates calcarifer, di kurung apung. Bull. Pen. Perikanan. Special Edition 1:21-26.

Mayunar, R. Purba dan S.A. Pranowo. 1990. Pertumbuhan dan kelulushidupan larva kakap putih (Lates calcarifer) pada berbagai kadar garam dan padat penebaran. J. Penelitian Budidaya Pantai, Terbitan Khusus 1:27-32.

Notowinarto dan H. Santosa. 1991. Pemijahan kakap putih (Lates calcarifer Bloch) dengan metoda manipulasi lingkungan. Buletin Budidaya Laut 1:814

Purba, R. dan Mayunar. 1990. Kelulushidupan dan pertumbuhan larva kakap putih, Lates calcarifer dari umur 8-30 hari pada berbagai salinitas. Bull. Pen. Perikanan. Special Edition 1:11-16.

Ramelan, S.H. 1998. Pengembangan budidaya ikan laut di Indonesia. Prosiding Seminar Teknologi Perikanan Pantai, Denpasar 6-7 Agustus 1998. p:59-79

Ramelan, S.H. 1999. Rencana pengembangan budi daya laut di Indonesia, rumusan hasil seminar budidaya laut di gedung Bidakara, 26-27 Agustus 1999. Prosiding Seminar Nasional Penelitian dan Diseminasi Teknologi Budidaya Laut dan Pantai, Jakarta 2 Desember 1999. p:17-21.

Redjeki, S., R. Purba dan P.T. Imanto. 1993. Pengkayaan rotifera untuk meningkatkan pertumbuhan dan kelangsungan hidup larva kakap putih (Lates calcarifer). J. Penelitian Budi Daya Pantai 9(5):6575

Santosa, H. dan Notowinarto. 1991. Pemijahan ikan kakap putih (Lates calcarifer Bloch) dengan metoda ransang hormonal. Buletin Budi Daya Laut 2:13-22.

Slamet, B., S. Diani dan P. Sunyoto. 1991. Pengaruh perbedaan prosentase penggantian air terhadap kelulushidupan dan pertumbuhan larva kakap puitih Lates calcarifer. Bull. Pen. Perikanan, Special Edition $1: 5-9$.

Sugama, K. 1999. Inventarisasi dan identifikasi teknolog budidaya laut dan pantai yang telah dikuasai untuk diseminasi. Prosiding Seminar Nasional Penelitian - dan Diseminasi Teknologi Budi Daya Laut dan Pantai, Jakarta 2 Desember 1999. p:61-72

Sumiarsa, G.S., T. Ahmad dan A. Prijono. 1994. Aplikasi teknik produksi benih ikan bandeng pada panti benih skala kecil: produksi dan kendala. Makalah pada Seminar Hasil Penelitian dan Pengembangan Perikanan Sulawesi Selatan, Maros, 5-7 Mei 1994 $18 \mathrm{p}$.

Sunyoto, P. dan A. Basyari. 1990. Pengaruh penundaan pemberian pakan nauplii Artemia pada pertumbuhan dan kelulushidupan larva kakap putih (Lates calcarifer). J. Penelitian Budidaya Pantai, Terbitan Khusus 1:53-57

Sunyoto, P., S. Redjeki dan S. Diani. 1990. Pengaruh waktu pemberhentian pakan rotifer terhadap kelulushidupan dan pertumbuhan larva kakap, Lates calcarifer. J. Penelitian Budidaya Pantai, Terbitan Khusus 1:24-26.

Supriatna, A., Muchari dan S. Yugo. 1990. Kultur masal larva kakap putih (Lates calcarifer). J. Penelitian Budidaya Pantai, Terbitan Khusus 1:10-16.

Supriatna, A., P. Sunyoto, S. Redjeki dan H. Kohno. 1991. Pemeliharaan massal larva ikan kakap putih, Lates calcarifer. Bull. Pen. Perikanan, Special Edition 2:3141.

Yasa, N.S., Z. Arifin dan U. Komarudin. 1999. Manipulasi lingkungan dalam pemijahan induk kakap putih (Lates calcarifer Bloch) asal tambak. Media Budi Daya Air Payau 1:21-28

Yunus, D. Roza dan K. Sugama. 1998. Pengaruh pemberian jenis fitoplankton yang berbeda terhadap sintasan larva kepiting bakau (Scylla serrata). Jurnal Penelitian Perikanan Indonesia 4(3):84-89 